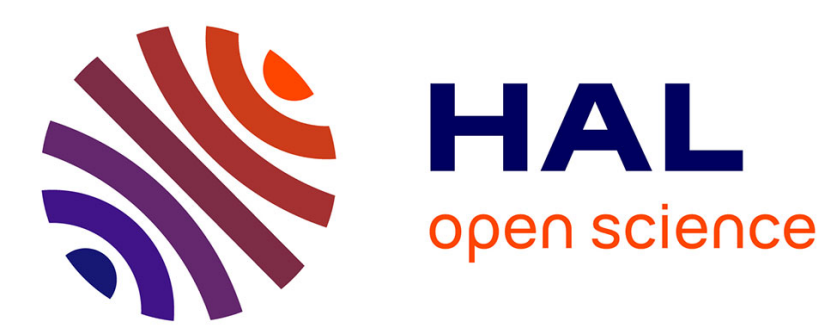

\title{
Ambiguity in electoral competition.
}

Jean-François Laslier

\section{To cite this version:}

Jean-François Laslier. Ambiguity in electoral competition.. 2003. hal-00242944

\section{HAL Id: hal-00242944 \\ https://hal.science/hal-00242944}

Preprint submitted on 6 Feb 2008

HAL is a multi-disciplinary open access archive for the deposit and dissemination of scientific research documents, whether they are published or not. The documents may come from teaching and research institutions in France or abroad, or from public or private research centers.
L'archive ouverte pluridisciplinaire HAL, est destinée au dépôt et à la diffusion de documents scientifiques de niveau recherche, publiés ou non, émanant des établissements d'enseignement et de recherche français ou étrangers, des laboratoires publics ou privés. 


\section{ECOLE POLYTECHNIQUE}

CENTRE NATIONAL DE LA RECHERCHE SCIENTIFIQUE

\section{Ambiguity in electoral competition}

Jean-François Laslier

Février 2003

Cahier $n^{\circ} \quad 2003-001$

\section{LABORATOIRE D'ECONOMETRIE}

1rue Descartes F-75005 Paris

(33) 155558215

http://ceco.polytechnique.fr/

mailto:labecox@poly.polytechnique.fr 


\title{
Ambiguity in electoral competition
}

\author{
Jean-François Laslier ${ }^{1}$
}

Février 2003

\author{
Cahier $^{\circ} \quad 2003-001$
}

Résumé: L'article propose une théorie de la compétition électorale ambigüe. Une plateforme est ambigüe si les votants peuvent l'interpréter de différentes manières. Une telle plate-forme met plus ou moins de poids sur sur les différentes options possibles de sorte qu'elle est plus ou moins facilement interprétée comme une politique ou une autre. On fait l'hypothèse que les partis politiques peuvent contrôler exactement leurs plate-formes mais ne peuvent pas cibler celles-ci vers les votants individuellement. Chaque électeur vote d'après son interprétation des plate-formes des partis mais est averse à l'ambiguité. On montre que ce jeu de compétition électorale n'a pas d'équilibre de Nash. Cependant ses stratégies max-min sont les stratégies optimales du jeu Downsien en stratégies mixtes. De plus, si les partis se comportent de manière suffisament prudente par rapport à l'aversion pour l'ambiguité des électeurs, ces mêmes stratégies forment un équilibre.

\begin{abstract}
The paper proposes a theory of ambiguous electoral competition. A platform is ambigous if voters may interpret it as different policy proposals. An ambiguous platform puts more or less emphasis on alternative policies so that it is more or less easily interpreted as one policy or the other. I suppose that a party can monitor exactly this platform design but cannot target its communications to individuals one by one. Each individual votes according to her understanding of the parties' platforms but dislikes ambiguity. It is shown that this electoral competition has no Nash equilibrium. Nevertheless its maxmin strategies are the optimal strategies of the Downsian game in mixed strategies. Furthermore, if parties behave prudently enough and if the voters aversion to ambiguity is small enough, these strategies do form an equilibrium.
\end{abstract}

Mots clés : $\quad$ Compétition électorale, Ambiguïté, Comportement prudent, jeux à somme nulle.

Key Words : Electoral competition, Ambiguity, Prudent behavior, Zero-sum games

Classification JEL: C72, D72

\footnotetext{
${ }^{1}$ Laboratoire d'économétrie, Ecole Polytechnique, 1 rue Descartes, F-75005 Paris. Courriel: laslier@poly.polytechnique.fr
} 


\section{Introduction}

\subsection{Position of the problem}

How to model ambiguity in electoral competition is a challenge for formal political science. One one hand, the fact that political speeches are ambiguous seems obvious. On the other hand, it seems to be the case that voters dislike parties' ambiguity. Then the usual assumption that political speeches are designed to please the electorate should lead politicians to make non-ambiguous statements. As they all say: "Let me be very clear..."

This paper offers a model in which parties are ambiguous at equilibrium, the essential reason being that they fear to loose if they were not. What is meant by "ambiguity" is that an ambiguous electoral platform can be interpreted in various ways as a possible policy by otherwise identical individuals. On the contrary, a non ambiguous platform is such that all individuals understand it in the same way. Formally, an ambiguous political platform is defined as a probability distribution over the set of possible policies. Consequently, the electoral competition that I study is technically related to the usual mixed extension of the standard Downsian game played in pure strategies. Indeed this paper can be seen as a justification of the mixed equilibrium of the plurality game as describing classical two-party Downsian competition.

It is a well-known property that electoral competition games played in mixed strategies have equilibria even in the absence of a Condorcet winner. Consideration of these equilibria is usually criticized on the basis that parties "do not toss coins". While it is certainly true that parties do not chose at random pure strategies, this critique is misplaced since it is only a critique of one possible interpretation of the linear extension of the pure strategy game, and it is indeed possible to find other interpretations of the same mathematical object, interpretations which might be immune to that particular critique. I propose such a model, in which parties toss no coin, and whose unique equilibrium can nevertheless be computed by solving the mixed-strategy plurality game. The main ingredients of the model are the following:

Voter behavior. A voter chooses which party to vote for on the basis of (i) what she understands to be the parties' policies and (ii) the degree of ambiguity of the platforms. In particular, voters dislike ambiguity. The consequence is that, in the absence of a Condorcet-winner policy, the Downsian game has no Nash equilibrium.

Party behavior. Parties behave "prudently"; electoral competition is a 
two-player, simultaneous move, zero-sum game. I make the hypothesis that a party maximizes a weighted sum of (i) its expected vote share and (ii) its minimum expected vote share. This behavioral assumption reflects a kind of risk aversion in a game situation. I show that the Downsian game has a prudent equilibrium.

This introduction discusses informally these points and makes the connection with the literature.

\subsection{Modeling ambiguity.}

The fact that politicians talks are ambiguous is well known and documented (Downs, 1957 [13]; Campbell, 1983 [10]). But even if political rhetoric and the cognitive determinant of persuasion are analyzed in details, few models are available that help understand the role of ambiguity within democratic political institutions ${ }^{1}$. The ambiguity of political discourse is certainly a complex phenomenon, which should be considered at both levels of the speaker and the listener (the "sender" and the "receiver"). For instance, even after a referendum, a situation in which at least the question raised is clear, one can wonder whether voters are able to explain or justify their votes $^{2}$.

This paper concentrates on ambiguity from the point of view of the sender (the political party). I will suppose that as soon as the message sent is clear the receiver (the voter) understands it clearly. The origin of ambiguity is therefore the political talk. As to the politician, ambiguity can be intentional or unintentional. Unintentional ambiguity arises from slips of the tongue, gestures or other kinds of unconscious behavioral signaling. More importantly, unintentional ambiguity is generated for a party by coordination problems within the party, when different speakers speak differently, and by the fact that political parties most often do not communicate directly with the electors: an important part of political information is mediated by journalists, if not hearsay or rumor. All these aspects are neglected here and the paper concentrates on strategic ambiguity.

Political communication is mass communication. If a politician was able to design a different talk for each elector, maybe each of these talks would be very clear. Actually, politicians can easily give way to the temptation of making different promises to different people. Here is for instance how

\footnotetext{
${ }^{1}$ Seminal papers are Shepsle, 1972 [31] and Page, 1976 [28].

${ }^{2}$ Blais, Martin and Nadeau, 1998 [7], after the 1995 referendum on Québec's sovereignty, allow for some optimism as to the voters' ability to justify their votes in a consistent way, once they are asked open questions and can answer in their own words.
} 
Lionel Jospin, the french prime minister and future socialist candidate for presidency, explained himself on that point in front of the militants of his party:

"Today I talked as a militant, faithful to the militant that I am. Under other circumstances, I will not have a different tough, I will not be moved by other values, but I will adopt a different tone, that will allow to bring our message to the French in their diversity." 3

An ambiguous electoral platform may be understood differently by individuals, and politicians would like to target their messages at different electors. For practical reasons, it is impossible to perfectly realize this targeting. From the normative point of view it is interesting to consider that a party can not at all target its communication at different voters. This simply corresponds to an hypothesis of equal information of the electors as to the party's platform. The present paper maintains this hypothesis, and excludes targeting.

One is consequently led to the following idea, which explains the model of political ambiguity to be used here. Consider (for instance) two policy positions for a party, say $x$ and $y$. The party can choose to express the non ambiguous position $x$ or the non ambiguous position $y$. It may also talk in such a way that some voters will understand that the proposal is $x$ and some will understand $y$; but the party cannot decide of which voter will understand $x$ and which voter will understand $y$.

This is the basic idea in our model of ambiguity. An ambiguous platform is a probability distribution $p$ over the set of policy positions such that for position $x, p(x)$ is the proportion of the electorate that understands $x$ from $p$. From the party's point of view, not being able to target voter $i$ means that $p(x)$ is the probability that voter $i$ understand $x$ from $p$, and this probability does not depends upon $i$ 's preference. In this paper it will be further assumed that the number of (pure) policy positions is finite, that a party can chose any probability distribution over the set of policy positions, that there are two parties, and that both parties have the same set of available policy positions.

\footnotetext{
${ }^{3}$ That was before the official annoncement that Jospin was candidate. "Aujourd'hui, j'ai parlé en militant, fidèle au militant que je suis. Dans d'autres conditions, je n'aurai pas une pensée différente, je ne serai pas animé par d'autres valeurs, mais j'adopterai une tonalité qui permettra de conduire notre message vers les Français dans leur diversité." Congrès Extraordinaire du Parti Socialiste, Paris, February 24, 2002.
} 


\section{$1.3 \quad$ Voters}

Voters dislike ambiguity. This sounds true, but it is not clear at all why they do so. In the present paper, the way I model voters disliking ambiguity is rather crude. I suppose that the ambiguity of a platform is measured by some exogenously given "ambiguity measure". This measure is provided by some function qualitatively similar to the entropy of the platform (the set of alternatives is finite, in other contexts this measure could be the variance). Then, with some probability that is proportional to the ambiguity of the party's platform, a voter infers from listening to the party's platform that "this party is fuzzy", and with the complement probability, the voter infers a definite policy. To keep things simple, I assume that the conclusion "this party is fuzzy" is the worst possible one: It will be said that the voter rejects the party, and she will not vote for such a party. ${ }^{4}$.

The coefficient of proportionality between the ambiguity measure and the probability of rejection is a parameter of the model that measures the voter's aversion to ambiguity. It is assumed that this coefficient is the same for all voters.

\subsection{Parties}

The objective of a party is to maximize its expected plurality ${ }^{5}$. There are two parties and the electoral competition is constant-sum. In the case where the voters' preference profile has a Condorcet winner policy, the electoral competition game between two parties has an equilibrium. In that equilibrium parties use non-ambiguous platforms. This classical result will be kept in our setting.

Consider now the case where the preference profile shows no Condorcet winner policy. If the voters are not adverse to ambiguity then the game has an equilibrium, and the equilibrium strategy is ambiguous (the equilibrum platform is computed by solving the plurality game in mixed strategies). The problem is that as soon as the voters' aversion to ambiguity is not exactly zero, this property is lost and the game has no equilibrium (Proposition 1).

The reason for that absence of equilibrium must be traced back to the fact that in a mixed-strategy equilibrium all pure strategies that are played

\footnotetext{
${ }^{4}$ Exept of course if this voter has also inferred that the other party is ambiguous, in which case I suppose that the she votes at random.

${ }^{5}$ As noticed in Laslier, 2000 [18], when $p(x)$ is not the probability that the whole electorate understands $x$ from $p$ but the proportion of voters that do so, and if the number of voters is large, maximizing the plurality is equivalent to maximizing the probability of winning.
} 
with some probability yield the same payoff. Here, the voters' aversion to ambiguity lowers the party's payoff for ambiguous platforms. The payoff function becomes convex rather than linear as it would be in a mixedstrategy game, so that equilibrium is lost.

The question is thus to predict the behavior of parties playing a constantsum game that has no equilibrium. To do so we rely on a concept of prudent behavior. This concept is valuable for behavioral game theory independently of the main subject matter of this paper, therefore the concept is developed with some details in an autonomous appendix. Recall that according to maximin behavior, the agent chooses the action that performs the best in the worst situation. This is always possible and, in a constant-sum twoplayer game, would be reasonable if the agent was to play first. According to best response behavior, the agent is supposed to choose the action that performs the best knowing the other player's action, but this is of course not always possible. I simply suppose that a player (a party) is endowed with a prudence parameter $\beta$, which weights in the player's objective the true utility level (which depends on the opponent's action) and the minimum utility (which does not). When $\beta$ goes from 0 to 1 , the agent's behavior goes from best response to maximin. The game in which players' objective is described by such a modified utility function is called the prudently modified game. A $\beta$-prudent equilibrium is just a Nash equilibrium of the corresponding prudently modified game.

Prudent behavior is in line with observations in Experimental Game Theory. Up to my knowledge the corresponding equilibrium notion developped in the present paper has not been mentioned explicitly in the literature, although it may sound familiar to scholars of zero-sum games. When it exists, prudent equilibrium enjoys very strong theoretical properties, similar both to strict Nash equilibrium for general games and to min-max equilibrium in zero-sum games. These properties are mentioned in the appendix. The typical example of such a situation is a zero-sum game with a unique and pure equilibrium.

The main result of the present paper is that the electoral competition has a prudent equilibrium even when no Condorcet winner policy exists, as soon as the ratio between the ambiguity aversion of the voters and the prudence of the parties is small enough (Theorem 4). Under that hypothesis, the outcome of two-party competition can thus be predicted. The prediction is that, in the absence of a Condorcet winner policy, parties chose to be ambiguous. Moreover, the equilibrium platform is the same for both parties and is simply obtained by solving the plurality game in mixed strategy. A basic example is provided in which computations can be performed 
explicitely (Proposition 8 in appendix B).

\subsection{Related literature}

Models of ambiguity in Politics should be placed within the literature on information transmission by the electoral process (see the survey Calvert, 1986 [9]). Under incomplete information, parties' proposals may at equilibrium look like ambiguous to voters, inasmuch the voters cannot infer from the platforms all what they would like to infer. The literature on ambiguity properly speaking tries to understand why and how incomplete information of the voters can arise for endogeneous strategic reasons even in a world of complete information.

The first, and certainly one natural way to model ambiguous policy proposal is to say that an "ambiguous" position is the announcement that the actual policy is to be chosen at random according to some probability distribution over the set of possible policies. That is proposing lotteries. Then one must endow the voters with preferences over lotteries. (Fishburn, 1972 [15]) and the simple way to do so is to suppose standard von Neuman and Morgenstein (vNM) utility functions on the side of the voters. It was early recognized (Zeckhauser, 1969 [32]) that this approach is bound to produce preference profiles with no Condorcet winner or, equivalently, models of electoral competition with no equilibrium. The reason is the following.

The set of lotteries $\Delta_{A}$ over a set $A$ of alternatives is a simplex; if $A$ has $k$ elements, then $\Delta_{A}$ is a compact subset of $\mathbb{R}^{k}$ of interior dimension $k-1$. A vNM utility function is a linear numerical function defined on $\Delta_{A}$ : indifference curves are hyperplanes. Voting over lotteries with vNM preferences is a special kind of "spatial voting". Conversely, any linear function on $\Delta_{A}$ is a vNM function on $A$. Therefore the requirement that individual preferences over lotteries satisfy the vNM axioms does not restrict further the set of admissible profiles on $A$. The "linear preferences" condition is the only one to add to the condition that the set of (now extended) alternatives is a simplex.

But we have learned from the study of spatial voting ${ }^{6}$ that majority voting in such an environment has in general no equilibrium, except with a single dimension. To obtain equilibrium in this framework, one must impose assumptions that are strong enough to restore equilibrium in $(k-1)$ dimension spatial voting with linear preferences.

Most authors use a one-dimensional framework and add various con-

${ }^{6}$ See the literature on "chaos" that follows McKelvey, 1976 [22]. 
sideration to obtain ambiguity at equilibrium. In Alesina and Cukierman, 1990 [1], candidates have their own ideal points and prefer not to commit exactly before the election. Meirowitz, 2000 [24], argues that candidates during the US primary elections may chose to remain ambiguous because they will be better informed at the moment of the general election. In Aragonès and Neeman, 2000 [2], voters are expected utility maximizers (they do not particularly like or dislike ambiguity), and the ambiguity level is a direct argument of the candidate utility function, not only a candidate wants to be elected but he wants to be elected on an ambiguous platform.

Another possibility that can work even without single-peaked and onedimensional preferences is to restrict the set of alternatives that are available as possible platforms to a party. For instance one may explore the hypothesis that all voters will anyway believe that there is a least a probability $1 / 2$ that a party will implement a given policy. (Reasons for that might be related to the party's past record.) If the two sets of possible policies for the two parties are disjoint, then instability can disappear. Aragonès and Postlewaite, 1999 [4], provide such an example, with 3 policies and 6 voters and such that one alternative is a Condorcet winner while not being the first choice of a majority of voters. Then ambiguity can persist at equilibrium.

The model proposed in the present paper does not restrict parties' strategy sets and it imposes no structure on the set of alternatives, except that the results are only demonstrated when this set is finite. It includes "voting over lotteries" as a special case, or more exactly discretized version of it. I suppose that similar results can be obtained in the infinite case (for instance in spatial voting), but this raises the technical difficulties associated with the study of games in which strategies are probability distributions over infinite sets.

Because it offers a justification for solving electoral competition plurality games in mixed strategies, the present paper must be also be related to the literature that uses mixed strategies in this context. The optimal strategies obtained at equilibrium are non degenerated in general, so they do not provide single policy predictions. Nevertheless, the support of the optimal strategies (the "Essential set") is a refinement of most of the usual majoritarian social choice correspondences such as the Top Cycle, which corresponds to iterated winning responses, or the Uncovered set, which corresponds to undominated strategies (see McKelvey, 1986 [23], Dutta and Laslier, 1999 [14], Banks, Duggan and Le Breton, 2002 [6]).

On economic domains, it can provide rather sharp predictions, contrasting with the common wisdom that two-party pure competition is unpredictable on more than one dimension. For instance in a model of voting 
over a taxation scheme, De Donder, 1998 [11, 12], computes that the Essential set represents about $1 \%$ of the set of alternatives while the Top cycle represents $63 \%$. In the pure redistribution ("Divide a dollar") setting it predicts that no voter will be promised more than twice the average share (Myerson, 1993 [25], Laslier and Picard, 2002 [20]) and it is used for tackling various political questions such as the US presidential campaigning system (see Brams and Davis 1974 [8] and the literature that followed), the provision of public goods (Persson and Tabellini, 2000 [30], Lizzeri and Persico, 2001 [21]), the treatment of minorities (Laslier, 2002 [19]) or campaign spendings regulations (Persico and Sahuguet, 2002 [29]). It can be extended to multi-party competition (Laffond, Laslier and Le Breton, 2000 [17]) and to dissymmetric two-party competition (Aragones and Palfrey, 2002 [3]).

\section{The model}

\subsection{Non-ambiguous platforms}

We consider a finite set $X$ of possible policy positions for parties. Elements of $X$ are object of preferences for the individuals; each individual $i \in \mathcal{I}$ is endowed with a preference relation $R_{i}$ over the set $X$. Following the Social Choice tradition, a "policy position" is a complete description of all relevant characteristics, for the voters to express informed preferences. Notice that the setting does not exclude parties proposing lotteries. There is no conceptual problem in considering that a particular policy position contains a statement like "The tax rate to be implemented will 5 or 10 percent, this will be decided after the election by tossing a coin". The only requirement is the existence of individual preference relations.

Since elements of $X$ are object of preferences, individuals can compare parties according to their positions: that is the benchmark model of electoral competition. With two parties, 1 and 2, if 1 adopts the position $x \in X$ and 2 adopts the position $y \in X$, individual $i$ votes for party 1 if she prefers $x$ to $y$. The net plurality in favor of $x$ against $y$ is the number:

$$
g(x, y)=\#\left\{i \in \mathcal{I}: x P_{i} y\right\}-\#\left\{i \in \mathcal{I}: y P_{i} x\right\} .
$$

From this definition, $g(y, x)+g(x, y)=0$, so that $g$ is the payoff function of a two-player, symmetric, zero-sum game

$$
\langle g,-g, X, X\rangle
$$


which we call the basic plurality game in pure strategies. As is wellknown, position $x$ is an optimal strategy for that symmetric zero-sum game if and only if $x$ is a Condorcet winner policy.

\subsection{Ambiguous platforms}

I define ambiguity as the fact that two individuals may interpret differently the same policy platform. A political platform is a mix of different policy positions. Formally this is simply a probability distribution over the set $X$. We denote by $p$ and $q$ the two parties' platforms:

$$
p, q \in \Delta_{X} .
$$

Clear-cut policy positions are degenerated platforms, which put probability one on an element $x \in X$, they will simply be denoted as elements of $X$ : $p \equiv x$. We will suppose that ambiguity is measured by some (exogenous) ambiguity function:

$$
\mathfrak{a}:\left\{\begin{array}{ccc}
\Delta_{X} & \rightarrow & \mathbb{R}_{+} \\
p & \mapsto & \mathfrak{a}(p)
\end{array}\right.
$$

which satisfy the two properties:

- $\mathfrak{a}(x)=0$ for all $x \in X$

- $\mathfrak{a}$ is strictly concave.

A standard example of such a function is the non-weighted "entropy":

$$
\mathfrak{e}(p)=-\sum_{x \in X} p(x) \log p(x) .
$$

According to this measure, the most ambiguous platform is the uniform one, which puts the same weight on every policy.

\subsection{Voters' behavior}

If $p(x)=1, \mathfrak{a}(p)=0$ and the party's platform is clear; all voters understand that the party is proposing policy $x$. If $\mathfrak{a}(p)>0$, then $p$ is positive on several alternative positions $x, x^{\prime}, \ldots$ I make the following assumption: some voters will understand that the party is proposing policy $x$, some will understand $x^{\prime}, \ldots$ and some will just conclude that "This party's platform is fuzzy". I assume that, when she has to decide which party to vote for, an individual always prefers a party who - according to her understanding - has proposed 
something, rather than a party whose platform she thinks is fuzzy. Choosing non-pure platforms is therefore costly for a party in terms of expected votes; this is how voters' aversion to ambiguity is incorporated in the party's payoff functions.

More precisely, I simply suppose that the number of voters who conclude from $p$ that " $p$ is fuzzy" is proportional to $p$ 's ambiguity. There is a positive number $\alpha_{1}$ (for party 1 ) such that the proportion of individuals that conclude from party 1 proposing $p$ that " $p$ is fuzzy" and thus reject 1 is:

$$
\mathfrak{a}_{1}(p)=\alpha_{1} \mathfrak{a}(p) .
$$

The proportion of individuals that understand $x$ from $p$ being then:

$$
\left(1-\mathfrak{a}_{1}(p)\right) p(x) .
$$

The same thing holds for party 2, with a parameter $\alpha_{2}$. To be completely precise and to maintain a tractable model, I also suppose that these proportions of individuals are independent from one party to another, and independent from individual preferences. Consider, for instance, that subset of the population with a given preference $R_{0}$. Among these individuals, a proportion $\mathfrak{a}_{1}(p) \mathfrak{a}_{2}(q)$ infers that both platforms are fuzzy. For $x \in X$, a proportion $\left(1-\mathfrak{a}_{1}(p)\right) p(x) \mathfrak{a}_{2}(q)$ thinks that platform 1 means $x$ and platform 2 is fuzzy, and for $y \in X$, a proportion $\left(1-\mathfrak{a}_{1}(p)\right)\left(1-\mathfrak{a}_{2}(q)\right) p(x) q(y)$ thinks that platform 1 means $x$ and platform 2 means $y$ (if $x$ is preferred to $y$ according to $R_{0}$, these individuals will vote for party 1 ). For these assumptions to make sense, it is needed that the population $\mathcal{I}$ is large, and then there is no problem in obtaining them as the outcome of a simple probabilistic model (see Laslier, 2000 [18]).

\subsection{The Ambiguous Plurality Game}

Under the previous assumptions, the net plurality in favor of party 1 against party 2 is:

$$
\begin{aligned}
u(p, q)= & \left(1-\mathfrak{a}_{1}(p)\right)\left(1-\mathfrak{a}_{2}(q)\right) g(p, q) \\
& +\left(1-\mathfrak{a}_{1}(p)\right) \mathfrak{a}_{2}(q)|\mathcal{I}| \\
& -\mathfrak{a}_{1}(p)\left(1-\mathfrak{a}_{2}(q)\right)|\mathcal{I}|
\end{aligned}
$$

where $|\mathcal{I}|$ is the total number of individuals and $g(p, q)$ denotes the expectation of $g(x, y)$ when $x, y \in X$ are independently chosen according to $p, q \in \Delta_{X}$ :

$$
g(p, q)=\sum_{x \in X} \sum_{y \in X} g(x, y) q(y) p(x) .
$$


The function $g$ is nothing but the payoff function of the basic plurality game in mixed strategies:

$$
\left\langle g,-g, \Delta_{X}, \Delta_{X}\right\rangle
$$

In this game, the objective of a party is the expected number of votes this party gets.

To save on notation, one can count plurality in proportion of the population and thus let $|\mathcal{I}|=1$. Rewriting, it comes:

$$
u(p, q)=\left(1-\mathfrak{a}_{1}(p)\right)\left(1-\mathfrak{a}_{2}(q)\right) g(p, q)-\left(\mathfrak{a}_{1}(p)-\mathfrak{a}_{2}(q)\right)
$$

The function $u$ is the payoff function of a zero-sum game:

$$
\left\langle u,-u, \Delta_{X}, \Delta_{X}\right\rangle
$$

which we call the ambiguous plurality game. Compared with the basic plurality game in mixed strategies it should be noticed first, that this game is no longer symmetric, unless $\alpha_{1}=\alpha_{2}$, and second (and more importantly), that the von Neumann theorem does not apply to this game, and indeed the game does not always have a solution. The following proposition precisely states when the ambiguous plurality game has a solution.

Proposition 1 (Non robustness of mixed Nash equilibria.) For any $\alpha_{1}, \alpha_{2}>$ 0 , a pair of strategies $(p, q) \in \Delta_{X} \times \Delta_{X}$ is a solution for the ambiguous plurality game $u$ if and only if $p$ and $q$ are pure, say $p \equiv x$ and $q \equiv y$ for some $x, y \in X$, and $x$ and $y$ are optimal strategies in the basic plurality game $g$. Thus if the basic plurality game $g$ has no pure solution then the ambiguous plurality game u has no solution.

Proof. Let $x, y \in X$ be optimal strategies for $g$. For any $p \in \Delta_{X}$ :

$$
\begin{aligned}
u(p, y) & =\left(1-\mathfrak{a}_{1}(p)\right) g(p, y)-\mathfrak{a}_{1}(p) \\
& \leq g(p, y) \\
& \leq g(x, y) .
\end{aligned}
$$

Likewise for all $q$ :

$$
g(x, y) \leq u(x, q)
$$

and it follows that $(x, y)$ is a solution for $u$.

Conversely let $(p, q)$ be a solution for $u$. From the linearity of the payoff function $g$ with respect to $p$, the first player has, according to $g$, a pure best response to $q$. Let $x$ be such a best response:

$$
g(x, q)=g(p, q)=\max _{p^{\prime} \in \Delta(x)} g\left(p^{\prime} q\right)=0 .
$$


If $\mathfrak{a}_{1}(p) \neq 0$, this implies that $u(x, q)>u(p, q)$; since $p$ is a best response to $q$ according to $u$, it must be the case that $p$ is pure. We can write $p \equiv x$ and (for the same reason) $q \equiv y$. Since pure strategies give the same payoff in both games, it must then be the case that $(x, y)$ is a solution for $g$. In the symmetric game $g$, this means that both $x$ and $y$ are optimal strategies.

This proposition enlightens a specific feature of mixed strategy equilibria: these equilibria are unstable with respect to voters' aversion to ambiguity. As soon as the parameters $\alpha_{1}$ and $\alpha_{2}$ that describe this aversion in our model, are not set to 0 exactly, existence of equilibrium is lost. However it is still the case that, provided that the parameters $\alpha_{1}, \alpha_{2}$ are small enough, an optimal (mixed) strategy for $g$ is a maximin strategy for $u$ :

Proposition 2 Let $p^{*}$ be an optimal strategy for $g$. If $\alpha_{1}$ is small enough then:

$$
\max _{p} \min _{q} u(p, q)=\min _{q} u\left(p^{*}, q\right) .
$$

Proof. Because $g$-best responses can be pure, it is easy to see that:

$$
\begin{aligned}
\min _{q} u(p, q) & =\left(1-\alpha_{1} \mathfrak{a}(p)\right) g_{\min }(p)-\alpha_{1} \mathfrak{a}(p) \\
\min _{q} u\left(p^{*}, q\right) & =-\alpha_{1} \mathfrak{a}\left(p^{*}\right) .
\end{aligned}
$$

Since $\alpha_{1} \mathfrak{a}(p) g_{\min }(p)$ is negative, it follows that:

$$
\min _{q} u(p, q)-\min _{q} u\left(p^{*}, q\right) \leq g_{\min }(p)-\alpha_{1}\left[\mathfrak{a}(p)-\mathfrak{a}\left(p^{*}\right)\right] .
$$

The function $p \mapsto g_{\min }(p)$ is linear and negative on each of the sets $B R^{-1}(y)=$ $\left\{p \in \Delta_{X}: g_{\min }(p)=g(p, y)\right\}$, and the function $p \mapsto \mathfrak{a}(p)-\mathfrak{a}\left(p^{*}\right)$ is concave. At $p=p^{*}, g_{\min }(p)=0=\alpha_{1}\left[\mathfrak{a}(p)-\mathfrak{a}\left(p^{*}\right)\right]$. Thus for $\alpha_{1}$ small enough $g_{\min }(p) \leq \alpha_{1}\left[\mathfrak{a}(p)-\mathfrak{a}\left(p^{*}\right)\right]$. There is a finite number of these sets $B R^{-1}(y)$ (because $X$ is supposed to be finite) and they cover $\Delta_{X}$. Therefore, if $\alpha_{1}$ is small enough, $g_{\min }(p) \leq \alpha_{1}\left[\mathfrak{a}(p)-\mathfrak{a}\left(p^{*}\right)\right]$ for all $p \in \Delta_{X}$. The result follows.

Of course, one cannot deduce from this remark that the pair $\left(p^{*}, p^{*}\right)$ of minimax strategies is a saddle point since, as soon as $\alpha_{1} \neq 0$ and $p$ is not pure, $\min _{q} u\left(p^{*}, q\right)=-\alpha_{1} \mathfrak{a}\left(p^{*}\right)<0=u\left(p^{*}, p^{*}\right)$. 


\subsection{Parties behavior}

We are left with a zero-sum game which has no equilibrium. In order to predict the outcome of that game, it is supposed that parties behavior is prudent. Each player $k=1,2$ is characterized by a "prudence" parameter $\beta_{k} \in[0,1]$ and maximizes a convex combination of its real utility (which depends on the opponent's behavior) and of the worst utility he can get. The prudently modified ambiguous plurality game (briefly: the prudent plurality game) is by definition the game:

$$
\left\langle\hat{u}_{1}, \hat{u}_{2}, \Delta_{X}, \Delta_{X}\right\rangle
$$

with:

$$
\begin{aligned}
& \hat{u}_{1}(p, q)=\left(1-\beta_{1}\right) u(p, q)+\beta_{1} u_{\min }(p) \\
& \hat{u}_{2}(p, q)=-\left(1-\beta_{2}\right) u(p, q)-\beta_{2} u_{\max }(q)
\end{aligned}
$$

and:

$$
\begin{aligned}
u_{\min }(p) & =\min _{q^{\prime} \in \Delta_{X}} u\left(p, q^{\prime}\right) \\
u_{\max }(q) & =\max _{p^{\prime} \in \Delta_{X}} u\left(p^{\prime}, q\right)
\end{aligned}
$$

A prudent equilibrium of the ambiguous plurality game $\left\langle u,-u, \Delta_{X}, \Delta_{X}\right\rangle$ is, by definition, a Nash equilibrium of the prudently modified ambiguous plurality game. It is easy to see that the prudent game $\hat{u}$ has the same minimax strategies as the game $u$, for instance for player $1,(3)$ obviously implies:

$$
\min _{q} \hat{u}_{1}(p, q)=u_{\min }(p) .
$$

Then proposition 2 writes:

Proposition 3 Let $p^{*}$ be an optimal strategy for $g$. If $\alpha_{1}$ is small enough then:

$$
\max _{p} \min _{q} \hat{u}_{1}(p, q)=\min _{q} \hat{u}_{1}\left(p^{*}, q\right)
$$

Prudent behavior in general zero-sum games is described in the appendix. In particular, two results are proved. First, any solution of the zero-sum game is a Nash equilibrium of the prudently modified game. Second, if the zero-sum game has a unique solution, then the corresponding Nash equilibrium is strict. We now raise the questions: When has the prudent plurality game an equilibrium? and What are these equilibria when they exist? Three simplifying will be used. 
1. Voters aversion to ambiguity is the same with respect to both parties:

$$
\alpha_{1}=\alpha_{2}=\alpha
$$

2. Parties' prudence parameters are the same:

$$
\beta_{1}=\beta_{2}=\beta
$$

3. The basic plurality game $\left\langle g,-g, \Delta_{X}, \Delta_{X}\right\rangle$ has a unique solution $\left(p^{*}, p^{*}\right)$.

It will be easily seen that our results are robust with respect to small variations in the two first of these hypothesis. As to the third hypothesis, if the game $g$ has several solutions then results can be found by considering the optimal strategies that are minimal with respect to the ambiguity measure. Notice that the uniqueness of the solution, in the case of a plurality game, holds under rather weak conditions: such is for instance the case if voters' preferences are linear orderings and there is an odd number of voters (Laffond, Laslier and Le Breton, 1997 [16]). Recall also that, unlike in general games, requiring uniqueness of equilibrium in a zero-sum game is not assuming away a coordination problem between the players, because equilibrium strategies of zero-sum games are interchangeable.

Theorem 4 Let $p^{*} \in \Delta_{X}$ be the unique optimal strategy of the basic plurality game $\left\langle g,-g, \Delta_{X}, \Delta_{X}\right\rangle$. If the ratio $\alpha / \beta$ is small enough, then $\left(p^{*}, p^{*}\right)$ is a strict Nash equilibrium of the prudent plurality game $\left\langle\hat{u}_{1}, \hat{u}_{2}, \Delta_{X}, \Delta_{X}\right\rangle$.

Proof. In order to prove this result, on just has to compute the difference $\hat{u}_{1}\left(p, p^{*}\right)-\hat{u}_{1}\left(p^{*}, p^{*}\right)$.

- If $p \neq p^{*}, u_{\min }(p)=u(p, y(p))$, where $y(p)$ is some pure $g$-best response to $p$. This is because $g$ is linear and therefore always admits pure best responses, and because ambiguity is zero on pure strategies. Thus for such a $y(p)$ :

$$
u_{\min }(p)=(1-\alpha \mathfrak{a}(p)) g(p, y(p))-\alpha \mathfrak{a}(p) .
$$

- If $p=p^{*}$, best responses to the optimal strategy $p^{*}$ give $g\left(p^{*}, y\left(p^{*}\right)\right)=$ 0 , because the value of the symmetric game $g$ is 0 , so:

$$
u_{\min }\left(p^{*}\right)=-\alpha \mathfrak{a}\left(p^{*}\right) .
$$


It follows that:

$$
\begin{aligned}
\hat{u}_{1}\left(p^{*}, p^{*}\right) & =(1-\beta) u\left(p^{*}, p^{*}\right)-\beta \alpha \mathfrak{a}\left(p^{*}\right) \\
& =-\beta \alpha \mathfrak{a}\left(p^{*}\right)
\end{aligned}
$$

and that, for $p \neq p^{*}$ :

$$
\hat{u}_{1}\left(p, p^{*}\right)=(1-\beta) u\left(p, p^{*}\right)+\beta(1-\alpha \mathfrak{a}(p)) g(p, y(p))-\beta \alpha \mathfrak{a}(p) .
$$

Notice that $g\left(p, p^{*}\right) \leq 0$, so:

$$
\begin{aligned}
u\left(p, p^{*}\right) & =(1-\alpha \mathfrak{a}(p))\left(1-\alpha \mathfrak{a}\left(p^{*}\right)\right) g\left(p, p^{*}\right)-\alpha\left(\mathfrak{a}(p)-\mathfrak{a}\left(p^{*}\right)\right) \\
& \leq-\alpha\left(\mathfrak{a}(p)-\mathfrak{a}\left(p^{*}\right)\right)
\end{aligned}
$$

thus:

$$
\hat{u}_{1}\left(p, p^{*}\right) \leq-(1-\beta) \alpha\left(\mathfrak{a}(p)-\mathfrak{a}\left(p^{*}\right)\right)+\beta(1-\alpha \mathfrak{a}(p)) g(p, y(p))-\beta \alpha \mathfrak{a}(p) .
$$

Computing the difference:

$$
f(p)=\hat{u}_{1}\left(p, p^{*}\right)-\hat{u}_{1}\left(p^{*}, p^{*}\right)
$$

one finds:

$$
f(p) \leq-\alpha\left(\mathfrak{a}(p)-\mathfrak{a}\left(p^{*}\right)\right)+\beta(1-\alpha \mathfrak{a}(p)) g(p, y(p))
$$

Using the fact that $g(p, y(p)) \leq 0$, one can write:

$$
f(p) \leq-\alpha\left(\mathfrak{a}(p)-\mathfrak{a}\left(p^{*}\right)\right)+\beta g(p, y(p))
$$

The function $p \mapsto g(p, y(p))$ is piecewise linear, its value is 0 at $p=p^{*}$ and is strictly negative at $p \neq p^{*}$. By assumption, the function $p \mapsto \mathfrak{a}(p)-\mathfrak{a}\left(p^{*}\right)$ is strictly concave and its value is 0 at $p=p^{*}$, it follows that if the ratio $\alpha / \beta$ is small enough, $g(p, y(p))<(\alpha / \beta)\left(\mathfrak{a}(p)-\mathfrak{a}\left(p^{*}\right)\right)$ for all $p \in \Delta_{X}$ such that $p \neq p^{*}$. Thus $f(p)<0$, which proves that $p^{*}$ is a strict best response to itself. By symmetry, $\left(p^{*}, p^{*}\right)$ is a strict Nash equilibrium. 


\section{A Prudent behavior in zero-sum games}

Let $S_{1}$ and $S_{2}$ be two sets. A simultaneous-move, two-person, zero-sum game

$$
\left\langle u,-u, S_{1}, S_{2}\right\rangle
$$

is defined by a function:

$$
u:\left\{\begin{aligned}
S_{1} \times S_{2} & \rightarrow \mathbb{R} \\
\left(s_{1}, s_{2}\right) & \mapsto u\left(s_{1}, s_{2}\right)
\end{aligned}\right.
$$

The (standard) assumption is made on the function $u$ that, for any $s_{1}$ and $s_{2}$ the numbers

$$
\begin{aligned}
u_{\min }\left(s_{1}\right) & =\min _{s_{2}^{\prime} \in S_{2}} u\left(s_{1}, s_{2}^{\prime}\right) \\
u_{\max }\left(s_{2}\right) & =\max _{s_{1}^{\prime} \in S_{1}} u\left(s_{1}^{\prime}, s_{2}\right)
\end{aligned}
$$

exist and correspond to some "best response" strategies. By definition, a pair of optimal strategies, or "solution", is a pair $\left(s_{1}^{*}, s_{2}^{*}\right) \in S_{1} \times S_{2}$ which forms a saddle-point, that is:

$$
u_{\max }\left(s_{2}^{*}\right)=u\left(s_{1}^{*}, s_{2}^{*}\right)=u_{\min }\left(s_{1}^{*}\right) .
$$

As it is well-known since von Neumann and Morgenstern, 1944 [27], such a pair exists if and only if two principles meet (see Bacharach, 1987 [5]):

According to the Equilibrium principle, a player chooses a best response to the other players' choices. This is certainly what the player would do if he was to play last. The Equilibrium principle is considered a necessary condition for rational choice (see for instance Myerson, 1999 [26]).

According to the Maximin principle, a player, when uncertain about the other players' choices, considers the worst situation for her. For instance for player 1 , this worst payoff is $u_{\min }\left(s_{1}\right)$. In a two-person, zero-sum game, considering the worst possible case is certainly what a player would do if she was to play first.

The rule of behavior embodied in the Maximin principle is wise but too extreme. In what follows, this principle is somehow weakened, hoping that the weakened version can match the Equilibrium principle. Given $\beta_{1} \geq 0$ and $\beta_{2} \geq 0$, let:

$$
\begin{aligned}
& \hat{u}_{1}\left(s_{1}, s_{2}\right)=\left(1-\beta_{1}\right) u\left(s_{1}, s_{2}\right)+\beta_{1} u_{\min }\left(s_{1}\right) \\
& \hat{u}_{2}\left(s_{2}, s_{1}\right)=-\left(1-\beta_{2}\right) u\left(s_{1}, s_{2}\right)-\beta_{2} u_{\max }\left(s_{2}\right)
\end{aligned}
$$


The new game $\left\langle\hat{u}_{1}, \hat{u}_{2}, S_{1}, S_{2}\right\rangle$ is called the prudently modified game for $\left\langle u,-u, S_{1}, S_{2}\right\rangle$, with parameters $\beta_{1}, \beta_{2}$. The function $\hat{u}_{k}$ can be interpreted as the payoff function to player $k$ if there is a probability $\left(1-\beta_{k}\right)$ that player $k$ plays the simultaneous-move game $u$ and a probability $\beta_{k}$ that player $k$ plays first (and the other player plays second) in a game with sequential moves and the same payoff function $u$. To state this more precisely, we consider a three-stage, extensive form game, whose tree is depicted in figure 1.

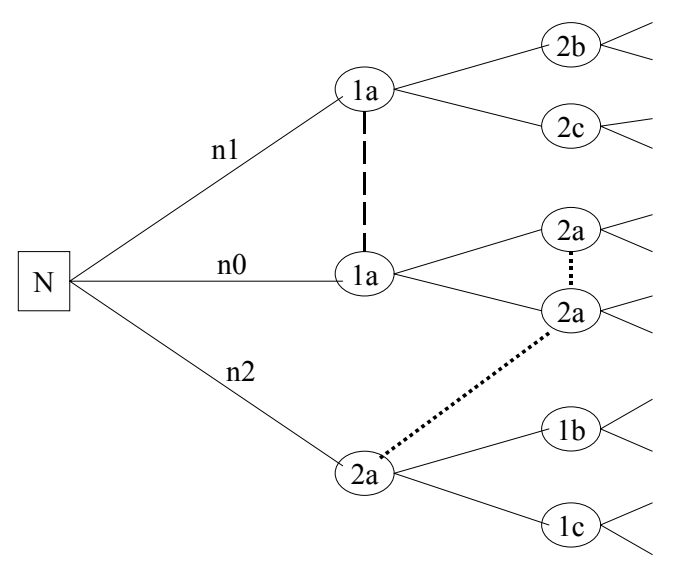

Figure 1: Extended Game

In this game, Nature moves first by selecting one out of three possibilities $n_{0}, n_{1}, n_{2}$. After $n_{0}$, players 1 and 2 play the simultaneous-move game $g$. After $n_{k}$, player $k$ moves before the other player. Player $k$ knows when she is playing after the other player, but does not know wether she is playing before him or wether they play simultaneously. For instance player 1 has $1+\# S_{2}$ information sets, where $\# S_{2}$ is the number (possibly infinite) of strategies in $g$ for player 2. Her first information set (labelled $1 a$ in the picture) corresponds to the situation in which she only knows that she is not playing second. The other information sets (in the picture, where $\# S_{1}=\# S_{2}=2$, they are labelled $1 b$ and $1 c$ ) correspond to her knowing which action player 2 has chosen. The description of the Extended game is complete once we let $\nu_{0}, \nu_{1}, \nu_{2}$, be the (common knowledge) probability of the three states of Nature.

When a players knows she is playing second, she plays ${ }^{7}$ a best response to the other player's observed action. The payoff $u$ being zero-sum, player

\footnotetext{
${ }^{7}$ By the usual dominance argument of backward induction.
} 
1 will get the payoff $\min _{s_{2} \in S_{2}} u\left(s_{1}, s_{2}\right)$ if player 2 plays second. Denote by $s_{1}$ and $s_{2}$ the (pure) strategies the players respectively play when they do not know they play second. When she does not know she is playing second, player 1 expected payoff is:

$$
\frac{\nu_{0}}{\nu_{0}+\nu_{1}} u\left(s_{1}, s_{2}\right)+\frac{\nu_{1}}{\nu_{0}+\nu_{1}} u_{\min }\left(s_{1}\right) .
$$

Letting $\beta_{1}=\frac{\nu_{1}}{\nu_{0}+\nu_{1}}$, this is nothing but the payoff $\hat{u}_{1}$ in equation (6). Thus solving for the Extended game amounts to solving for the simultaneousmove game defined by $\hat{u}=\left(\hat{u}_{1}, \hat{u}_{2}\right)$ in equations (6) and (7).

Proposition 5 If $\left(s_{1}^{*}, s_{2}^{*}\right)$ is a solution of the zero-sum game $u$, then $\left(s_{1}^{*}, s_{2}^{*}\right)$ is a Nash equilibrium for the prudently modified game $\hat{u}$.

Proof. Let $s_{1} \in S_{1}$. Because of the min in the definition of $\hat{u}_{1}$ :

$$
\hat{u}_{1}\left(s_{1}, s_{2}^{*}\right) \leq u\left(s_{1}, s_{2}^{*}\right)
$$

Because $s_{1}^{*}$ is a $g$-best response to $s_{2}^{*}$ :

$$
u\left(s_{1}, s_{2}^{*}\right) \leq u\left(s_{1}^{*}, s_{2}^{*}\right) .
$$

Because, for player $2, s_{2}^{*}$ is a best response to $s_{1}^{*}$ in the zero-sum game $u$ :

$$
u\left(s_{1}^{*}, s_{2}^{*}\right)=\min _{s_{2}^{\prime} \in S_{2}} u\left(s_{1}^{*}, s_{2}^{\prime}\right),
$$

therefore:

$$
u\left(s_{1}^{*}, s_{2}^{*}\right)=\hat{u}_{1}\left(s_{1}^{*}, s_{2}^{*}\right),
$$

and we find that $\hat{u}_{1}\left(s_{1}, s_{2}^{*}\right) \leq \hat{u}_{1}\left(s_{1}^{*}, s_{2}^{*}\right)$. The same reasoning for the other player completes the proof.

In the next proposition, a strict Nash equilibrium is a Nash equilibrium such that, for any player, any alternative action provides a payoff strictly lower than the equilibrium payoff.

Proposition 6 If $\left(s_{1}^{*}, s_{2}^{*}\right)$ is the unique solution of the zero-sum game $u$, then $\left(s_{1}^{*}, s_{2}^{*}\right)$ is the unique Nash equilibrium for the prudently modified game $\hat{u}$, and this equilibrium is strict. 
Proof. To prove uniqueness, for any couple of strategies $\left(s_{1}, s_{2}\right) \neq$ $\left(s_{1}^{*}, s_{2}^{*}\right)$, consider the responses $s_{1}^{*}$ and $s_{2}^{*}$ in the game $\widehat{u}$ for the two players:

$$
\begin{aligned}
\Delta_{1}= & \hat{u}_{1}\left(s_{1}^{*}, s_{2}\right)-\hat{u}_{1}\left(s_{1}, s_{2}\right) \\
= & \left(1-\beta_{1}\right)\left[u_{1}\left(s_{1}^{*}, s_{2}\right)-u_{1}\left(s_{1}, s_{2}\right)\right] \\
& +\beta_{1}\left[v_{1}-\min _{t_{2}} u_{1}\left(s_{1}, t_{2}\right)\right] \\
\Delta_{2}= & \hat{u}_{2}\left(s_{1}, s_{2}^{*}\right)-\hat{u}_{2}\left(s_{1}, s_{2}\right) \\
= & \left(1-\beta_{2}\right)\left[u_{2}\left(s_{1}, s_{2}^{*}\right)-u_{2}\left(s_{1}, s_{2}\right)\right] \\
& +\beta_{2}\left[v_{2}-\min _{t_{1}} u_{2}\left(t_{1}, s_{2}\right)\right]
\end{aligned}
$$

where $v_{1}=\min _{t_{2}} u\left(s_{1}, t_{2}\right)$ is the value of the zero-sum game $u$ for the first player and $v_{2}=-v_{1}$ is the value for the second player. Summing and taking into account the different prudent parameters, one gets:

$$
\begin{aligned}
\frac{\Delta_{1}}{1-\beta_{1}}+\frac{\Delta_{2}}{1-\beta_{2}}= & u_{1}\left(s_{1}^{*}, s_{2}\right)+u_{2}\left(s_{1}, s_{2}^{*}\right) \\
& +\frac{\beta_{1}}{1-\beta_{1}}\left[v_{1}-\min _{t_{2}} u_{1}\left(s_{1}, t_{2}\right)\right] \\
& +\frac{\beta_{2}}{1-\beta_{2}}\left[v_{2}-\min _{t_{1}} u_{2}\left(t_{1}, s_{2}\right)\right] .
\end{aligned}
$$

Because $\left(s_{1}^{*}, s_{2}^{*}\right)$ is an equilibrium, $u_{1}\left(s_{1}^{*}, s_{2}\right)+u_{2}\left(s_{1}, s_{2}^{*}\right) \leq u_{1}\left(s_{1}^{*}, s_{2}^{*}\right)+$ $u_{2}\left(s_{1}^{*}, s_{2}^{*}\right)=0$, hence the first term is non-negative. By definition, $v_{1} \geq$ $\min _{t_{2}} u_{1}\left(s_{1}, t_{2}\right)$ and $v_{2} \geq \min _{t_{1}} u_{2}\left(t_{1}, s_{2}\right)$, but because $\left(s_{1}, s_{2}\right)$ is not a solution for $u$, at least one of these two inequalities is strict. Therefore $\frac{\Delta_{1}}{1-\beta_{1}}+\frac{\Delta_{2}}{1-\beta_{2}}>0$ and one of the two numbers $\Delta_{1}$ and $\Delta_{2}$ is positive. Thus $\left(s_{1}, s_{2}\right)$ is not a Nash equilibrium of $\widehat{u}$.

Suppose that $\left(s_{1}^{*}, s_{2}^{*}\right)$ is not strict. For instance, let $s_{1} \neq s_{1}^{*}$ be such that $\hat{u}_{1}\left(s_{1}, s_{2}^{*}\right)=\hat{u}_{1}\left(s_{1}^{*}, s_{2}^{*}\right)$. Then the inequalities in the previous proof are equalities, in particular the first one (8):

$$
\hat{u}_{1}\left(s_{1}, s_{2}^{*}\right)=u\left(s_{1}, s_{2}^{*}\right) .
$$

This implies by definition of $\hat{u}_{1}$ that:

$$
u\left(s_{1}, s_{2}^{*}\right)=\min _{s_{2}^{\prime} \in S_{2}} u\left(s_{1}, s_{2}^{\prime}\right) .
$$

In the zero-sum game $u$, this means that $s_{2}^{*}$ is a best response for player 2 to $s_{1}$. The inequality (9) is an equality too:

$$
u\left(s_{1}, s_{2}^{*}\right)=u\left(s_{1}^{*}, s_{2}^{*}\right),
$$


therefore $s_{1}$, like $s_{1}^{*}$ is a best response to $s_{2}^{*}$. It follows that $\left(s_{1}, s_{2}^{*}\right)$ is an equilibrium for $u$, contradicting uniqueness.

As the Maximin principle, the property that a solution is a maximin profile also transfers from the zero-sum game to its non zero-sum prudent modification. Say that the strategy profile $\left(s_{1}^{*}, s_{2}^{*}\right)$ is a maximin profile for $\hat{u}$ if:

$$
\begin{aligned}
& \hat{u}_{1}\left(s_{1}^{*}, s_{2}^{*}\right)=\min _{s_{2}} \hat{u}_{1}\left(s_{1}^{*}, s_{2}\right)=\max _{s_{1}} \min _{s_{2}} \hat{u}_{1}\left(s_{1}, s_{2}\right), \\
& \hat{u}_{2}\left(s_{1}^{*}, s_{2}^{*}\right)=\min _{s_{1}} \hat{u}_{2}\left(s_{1}, s_{2}^{*}\right)=\max _{s_{2}} \min _{s_{1}} \hat{u}_{2}\left(s_{1}, s_{2}\right) .
\end{aligned}
$$

The definition is here stated for the game $\hat{u}$, but can be given for any game. The definition is well illustrated by the following game (game 1):

\begin{tabular}{c|c|c|} 
(game 1) & $\mathrm{L}$ & $\mathrm{R}$ \\
\hline $\mathrm{U}$ & $(0,0)$ & $(1,2)$ \\
\hline $\mathrm{D}$ & $(2,1)$ & $(-1,-1)$ \\
\hline
\end{tabular}

Game 1 has two Nash profiles, (U,R) and (D,L), and a maximin profile (U,L). Notice also that a maximin profile is more than a collection of strategies each of which independently maximizes the player's minimal payoff. For instance in the game:

\begin{tabular}{c|c|c} 
(game 2) & $\mathrm{L}$ & $\mathrm{R}$ \\
\hline $\mathrm{U}$ & $(1,1)$ & $(0,2)$ \\
\hline $\mathrm{D}$ & $(2,0)$ & $(-1,-1)$ \\
\hline
\end{tabular}

the maximin strategies are $\mathrm{U}$ and $\mathrm{L}$, like in the previous example; but (U,L) is not a Maximin profile because the max min for the line player obtains when she plays $\mathrm{U}$ and her opponent plays R (instead of L). Game 2 has no Maximin profile.

Proposition 7 If $\left(s_{1}^{*}, s_{2}^{*}\right)$ is a solution of the zero-sum game $u$, then $\left(s_{1}^{*}, s_{2}^{*}\right)$ is a maximin profile for the prudently modified game $\hat{u}$.

Proof. First notice that, as a straightforward consequence of the definition of $\hat{u}$, for any $s_{1} \in S_{1}$ :

$$
\min _{s_{2}} \hat{u}_{1}\left(s_{1}, s_{2}\right)=\min _{s_{2}} u\left(s_{1}, s_{2}\right) .
$$

Let $\left(s_{1}^{*}, s_{2}^{*}\right)$ be a solution of $u$, then $u\left(s_{1}^{*}, s_{2}^{*}\right)=\min _{s_{2}} u\left(s_{1}^{*}, s_{2}\right)$ implies that:

$$
\hat{u}_{1}\left(s_{1}^{*}, s_{2}^{*}\right)=u\left(s_{1}^{*}, s_{2}^{*}\right),
$$


and (10) gives:

$$
u\left(s_{1}^{*}, s_{2}^{*}\right)=\min _{s_{2}} u\left(s_{1}^{*}, s_{2}\right)=\min _{s_{2}} \hat{u}_{1}\left(s_{1}^{*}, s_{2}\right),
$$

so that we proved the first point:

$$
\hat{u}_{1}\left(s_{1}^{*}, s_{2}^{*}\right)=\min _{s_{2}} \hat{u}_{1}\left(s_{1}^{*}, s_{2}\right) .
$$

Next, for any $s_{1}$ :

$$
\begin{aligned}
\min _{s_{2}} \hat{u}_{1}\left(s_{1}, s_{2}\right) & \leq \hat{u}_{1}\left(s_{1}, s_{2}^{*}\right) \\
& =(1-\beta) u\left(s_{1}, s_{2}^{*}\right)+\beta u_{\min }\left(s_{1}\right) \\
& \leq u\left(s_{1}^{*}, s_{2}^{*}\right)=\hat{u}_{1}\left(s_{1}^{*}, s_{2}^{*}\right) \\
& =\min _{s_{2}} \hat{u}_{1}\left(s_{1}^{*}, s_{2}\right)
\end{aligned}
$$

gives the second point:

$$
\hat{u}_{1}\left(s_{1}^{*}, s_{2}^{*}\right)=\max _{s_{1}} \min _{s_{2}} \hat{u}_{1}\left(s_{1}, s_{2}\right) .
$$

The same reasoning is of course valid for the other player, hence the result. 


\section{B Example: the Condorcet 3-cycle}

The simplest situation in which the Downsian game has no pure equilibrium involves 3 alternatives forming a "Condorcet cycle". Let the set of alternatives be:

$$
X=\{a, b, c\}
$$

and the basic plurality be given by the matrix:

\begin{tabular}{c|c|c|c|}
$g(\cdot, \cdot)$ & $a$ & $b$ & $c$ \\
\hline$a$ & 0 & +1 & -1 \\
\hline$b$ & -1 & 0 & +1 \\
\hline$c$ & +1 & -1 & 0 \\
\hline
\end{tabular}

This situation is called the simple 3-cycle (the game is the standard Paper, Rock, Scissors game). It is easy to see that the unique optimal strategy is:

$$
p^{*}=(1 / 3,1 / 3,1 / 3)
$$

Proposition 8 In the simple 3-cycle, suppose that the voters measures ambiguity of a platform by its entropy with respect to the uniform distribution. Let $\alpha$ be the aversion of voters to ambiguity and let $\beta$ be the prudence parameter of both parties. Then, if

$$
\frac{\alpha}{\beta} \leq \frac{1}{\log 4} \simeq .72
$$

$\left(p^{*}, p^{*}\right)$ is an equilibrium of the prudent game.

Proof. In order to find the conditions for $\left(p^{*}, p^{*}\right)$ to be an equilibrium of the prudent game, one computes, for any $p \in \Delta_{X}$ :

$$
\begin{aligned}
& g\left(p, p^{*}\right)=0 \\
u\left(p, p^{*}\right)= & \alpha \mathfrak{a}\left(p^{*}\right)-\alpha \mathfrak{a}(p) \\
u_{\min }(p)= & (1-\alpha \mathfrak{a}(p)) g_{\min }(p)-\alpha \mathfrak{a}(p) \\
\hat{u}_{1}\left(p, p^{*}\right)= & (1-\beta) u\left(p, p^{*}\right)+\beta u_{\min }(p) \\
= & (1-\beta) \alpha\left(\mathfrak{a}\left(p^{*}\right)-\mathfrak{a}(p)\right) \\
& +\beta(1-\alpha \mathfrak{a}(p)) g_{\min }(p)-\beta \alpha \mathfrak{a}(p) \\
\hat{u}_{1}\left(p^{*}, p^{*}\right)= & -\beta \alpha \mathfrak{a}\left(p^{*}\right)
\end{aligned}
$$




$$
\begin{aligned}
f(p) & =\hat{u}_{1}\left(p, p^{*}\right)-\hat{u}_{1}\left(p^{*}, p^{*}\right) \\
& =\alpha\left(\mathfrak{a}\left(p^{*}\right)-\mathfrak{a}(p)\right)+\beta(1-\alpha \mathfrak{a}(p)) g_{\min }(p)
\end{aligned}
$$

The value $g_{\min }(p)$ is easily computed; this minimum value is obtained for one of the three pure strategies

$$
\begin{aligned}
g_{\min }(p) & =\min \{g(p, a), g(p, b), g(p, c)\} \\
& =\min \{p(c)-p(b), p(a)-p(c), p(b)-p(a)\}
\end{aligned}
$$

The platforms $p$ such that $g_{\min }(p)=p(c)-p(b)$ are the ones such that $a$ is a best response to $p$. It is a convex subset of $\Delta_{X}$, defined by the inequalities $g(p, a) \leq g(p, x)$, for $x=b, c$. We can denote this set as:

$$
B R^{-1}(a)=\left\{p \in \Delta_{X}: g_{\min }(p)=g(p, a)\right\}
$$

Here:

$$
B R^{-1}(a)=\left\{p \in \Delta_{X}: p(c) \leq 1 / 3 \leq p(b)\right\}
$$

and $B R^{-1}(a)$ is a convex polyhedron whose four extreme points are:

$$
(0,1,0),\left(0, \frac{2}{3}, \frac{1}{3}\right),\left(\frac{1}{3}, \frac{1}{3}, \frac{1}{3}\right),\left(\frac{2}{3}, \frac{1}{3}, 0\right) .
$$

On $B R^{-1}(a)$ the function we wish to be negative is:

$$
f(p)=\alpha\left(\mathfrak{a}\left(p^{*}\right)-\mathfrak{a}(p)\right)+\beta(1-\alpha \mathfrak{a}(p))(p(c)-p(b)) .
$$

One can majorize:

$$
f(p) \leq \alpha\left(\mathfrak{a}\left(p^{*}\right)-\mathfrak{a}(p)\right)+\beta(p(c)-p(b))=\delta(p) .
$$

At the extreme points of $B R^{-1}(a)$ one finds:

$$
\begin{aligned}
\delta(0,1,0) & =\alpha \mathfrak{a}\left(p^{*}\right)-\beta \\
\delta\left(0, \frac{2}{3}, \frac{1}{3}\right) & =\alpha\left(\mathfrak{a}\left(p^{*}\right)-\mathfrak{a}\left(0, \frac{2}{3}, \frac{1}{3}\right)\right)-\frac{\beta}{3} \\
\delta\left(\frac{1}{3}, \frac{1}{3}, \frac{1}{3}\right) & =0 \\
\delta\left(\frac{2}{3}, \frac{1}{3}, 0\right) & =\alpha\left(\mathfrak{a}\left(p^{*}\right)-\mathfrak{a}\left(\frac{2}{3}, \frac{1}{3}, 0\right)\right)-\frac{\beta}{3}
\end{aligned}
$$

Taking the entropy as the measure of ambiguity:

$$
\begin{aligned}
\mathfrak{a}\left(p^{*}\right) & =\mathfrak{e}\left(p^{*}\right)=\log 3 \\
\mathfrak{a}\left(0, \frac{2}{3}, \frac{1}{3}\right) & =\mathfrak{a}\left(\frac{2}{3}, \frac{1}{3}, 0\right)=\log 3-\frac{2}{3} \log 2
\end{aligned}
$$


so that:

$$
\begin{aligned}
f(0,1,0) & =\alpha \log 3-\beta \\
f\left(0, \frac{2}{3}, \frac{1}{3}\right) & =\alpha \frac{2}{3} \log 2-\frac{\beta}{3} \\
f\left(\frac{1}{3}, \frac{1}{3}, \frac{1}{3}\right) & =0
\end{aligned}
$$

(and $f\left(\frac{2}{3}, \frac{1}{3}, 0\right)=f\left(0, \frac{2}{3}, \frac{1}{3}\right)$.) We therefore find two conditions for $f$ to be negative at the extreme points of $B R^{-1}(a)$. The first one, $\beta \geq \alpha \log 3$, is implied by the second, $\beta \geq \alpha \log 4$, which is precisely the equation (11) stated in the proposition. This equation is a sufficient condition for $f$ to be negative at the extreme points of $B R^{-1}(a)$.

A sufficient condition for $\delta$, and thus $f$, to be negative on the whole set $B R^{-1}(a)$ is then that $\delta$ be convex on that set. Notice that $\delta$, as a function of $p$, is the sum of a constant $\alpha \mathfrak{a}\left(p^{*}\right)$, a linear function $+\beta(p(c)-p(b))$, and the function $-\alpha \mathfrak{a}(p)$, which is convex by assumption; thus $\delta$ is convex, and (11) is sufficient for $f$ to be positive on $B R^{-1}(a)$. The same condition obviously works for $B R^{-1}(b)$ and $B R^{-1}(c)$, so that (11) is sufficient for $f$ to be negative for all $p$. 


\section{References}

[1] Alberto Alesina and Alex Cukierman. The politics of ambiguity. Quaterly Journal of Economics, 105:829-850, 1990.

[2] Enriqueta Aragones and Zvika Neeman. Strategic ambiguity in electoral competition. Journal of Theoretical Politics, 12:183-204, 2000.

[3] Enriqueta Aragones and Thomas R. Palfrey. Mixed equilibria in a Downsian model with a favored candidate. Journal of Economic Theory, 103:131-161, 2002.

[4] Enriqueta Aragones and Andrew Postlewaite. Ambiguity in Election Games, 1999. mimeo.

[5] Michael Bacharach. Zero-sum games. In John Eatwell, Murray Milgate, and Peter Newman, editors, The New Palgrave: A Dictionary of Economics. Macmillan, London, 1987.

[6] Jeffrey S. Banks, John Duggan, and Michel Le Breton. Bounds for mixed strategy equilibria and the spatial model of elections. Journal of Economic Theory, 103:88-105, 2002.

[7] André Blais, Pierre Martin, and Richard Nadeau. Can people explain their own vote? introspective questions as indicator of salience in the 1995 Quebec referendum on sovereignty. Quality and Quantity, 32:355366, 1998.

[8] Steven J. Brams and Morton D. Davis. The 3/2's rule in presidential campaigning. American Political Science Review, 68:113-134, 1974.

[9] Randall L. Calvert. Models of Imperfect Information in Politics. Fundamentals of Pure and Applied Economics. Harwood Academic Publisher, Chur, 1986.

[10] James E. Campbell. Ambiguity in the issue positions of presidential candidates: A causal analysis. American Journal of Political Science, 27:284-293, 1983.

[11] Philippe De Donder. The Political Economy of Redistribution. PhD thesis, Université de Namur, 1998.

[12] Philippe De Donder. Majority voting solution concepts and redistributive taxation: Survey and simulations. Social Choice and Welafre, 17:601-627, 2000 . 
[13] Anthony Downs. An Economic Theory of Democracy. Harper, New York, 1957.

[14] Bhaskar Dutta and Jean-François Laslier. Comparison functions and choice correspondences. Social Choice and Welfare, 16 :513-532, 1999.

[15] Peter C. Fishburn. Lotteries and social choice. Journal of Economic Theory, 5:189-207, 1972.

[16] Gilbert Laffond, Jean-François Laslier, and Michel Le Breton. A theorem on symmetric two-player zero-sum games. Journal of Economic Theory, 72:426-431, 1997.

[17] Gilbert Laffond, Jean-François Laslier, and Michel Le Breton. $k$-player additive extension of two-player games, with an application to the Borda electoral competition game. Theory and Decision, 48:129-137, 2000 .

[18] Jean-François Laslier. Interpretation of electoral mixed strategies. Social Choice and Welfare, 17:283-292, 2000.

[19] Jean-François Laslier. How two-party competition treats minorities. Economic Design, 7:297-307, 2002.

[20] Jean-François Laslier and Nathalie Picard. Distributive politics and electoral competition. Journal of Economic Theory, 103:106-130, 2002.

[21] Alessandro Lizzeri and Nicola Persico. The provision of public goods under alternative electoral incentives. American Economic Review, 91:225-239, 2001.

[22] Richard D. McKelvey. Intransitivities in multidimensional voting models and some implication for agenda control. Journal of Economic Theory, 12:472-482, 1976.

[23] Richard D. McKelvey. Covering, dominance, and institution-free properties of social choice. American Journal of Political Science, 30:283$314,1986$.

[24] Adam Meirowitz. Informational Party Primaries and Strategic Ambiguity. Stanford University, 2000. mimeo.

[25] Roger B. Myerson. Incentives to cultivate favored minorities under alternative electoral systems. American Political Science Review, 87(4):856-869, December 1993. 
[26] Roger B. Myerson. Nash equilibrium and the history of economic theory. Journal of Economic Literature, 37:1067-1082, 1999.

[27] John Von Neumann and Oskar Morgenstern. Theory of Games and Economic Behavior. Princeton University Press, Princeton, 1944.

[28] Benjamin I. Page. The theory of political ambiguity. American Political Science Review, 70:742-752, 1976.

[29] Nicola Persico and Nicolas Sahuguet. Campaign Spending Regulation in a Model of Redistributive Politics, 2002. mimeo.

[30] Torsten Persson and Guido Tabellini. Political Economics: Explaining Economic Policy. MIT Press, Cambridge, 2000.

[31] Kenneth A. Shepsle. The strategy of ambiguity: Uncertainty and electoral competition. American Political Science Review, 66:555-568, 1972 .

[32] Richard Zeckhauser. Majority rule with lotteries on alternatives. Quaterly Journal of Economics, 83:696-703, 1969. 